\section{Self-monitoring of blood glucose did not improve glycaemic control in patients with type 2 diabetes not treated with insulin}

\section{STUDY DESIGN}

Design: randomised controlled trial (Diabetes Glycaemic Education and Monitoring [DiGEM] study).

Allocation: concealed. *

Blinding: blinded (laboratory staff).*

\section{STUDY QUESTION}

Setting: 48 general practices in Oxfordshire and South Yorkshire, UK.

Patients: 453 patients $\geqslant 25$ years of age at diagnosis of type 2 diabetes (mean age $66 \mathrm{y}$ at study entry, 57\% men, median duration of diabetes $3 \mathrm{y}$ ) who were managed with diet or oral hypoglycaemic agents alone, had haemoglobin $\mathrm{A}_{1 \mathrm{c}}\left(\mathrm{HbA}_{1 \mathrm{c}}\right)$ level $\geqslant 6.2 \%$ (mean $7.5 \%$ ), and were independent in activities of daily living. Exclusion criteria included serious disease and use of a blood glucose meter $\geqslant 2$ times/week in the previous 3 months. Intervention: self-testing by use of a blood glucose meter 3 times daily 2 days/week, with instructions to contact their physician if readings were consistently high or low (self-testing group, $\mathrm{n}=150$ ); self-testing (as above) plus training in timing, interpreting, and using the test results (self-monitoring group, $\mathrm{n}=151$ ); or quarterly blood glucose tests but no use of a blood glucose meter (control group, $\mathrm{n}=152$ ). All patients received usual care, including training in behaviour-changing techniques and feedback on glycaemic control.

Outcomes: change in $\mathrm{HbA}_{1 \mathrm{c}}$ level, blood pressure, cholesterol, weight, and body mass index; and hypoglycaemic episodes.

Follow-up period: 12 months.

Patient follow-up: $87 \%$ (intention-to-treat analysis).

\section{MAIN RESULTS}

At 12 months, groups did not differ for change in $\mathrm{HbA}_{1 \mathrm{c}}$ level (table), blood pressure, weight, body mass index, or ratio of total cholesterol to high-density lipoprotein cholesterol Decrease in total cholesterol level was greater in the selfmonitoring group than in the control group. Risk of hypoglycaemia was highest in the self-monitoring group (table).

\section{CONCLUSION}

Blood glucose self-testing or self-monitoring did not improve glycaemic control in patients with type 2 diabetes not treated with insulin.

* See glossary.

Abstract and commentary also appear in ACP Journal Club.

Self-testing with a blood glucose meter (ST) $v$ self-monitoring (SM) $v$ no use of a meter (control) in type 2 diabetes not treated with insulin*

\begin{tabular}{lccrll}
\hline $\begin{array}{l}\text { Outcomes at } \\
\mathbf{1 2} \text { months }\end{array}$ & ST & SM & Control & $\begin{array}{l}\text { Difference in mean change } \\
\text { (95\% Cl) }\end{array}$ \\
\hline $\begin{array}{l}\text { Haemoglobin } \\
\mathrm{A}_{1 \mathrm{c}}{ }^{\dagger}\end{array}$ & $-0.14 \%$ & - & $0.00 \%$ & $-0.14 \%(-0.35$ to 0.07$)$ \\
\hline & - & $-0.17 \%$ & $0.00 \%$ & $-0.17 \%(-0.37$ to 0.03$)$ \\
\hline $\begin{array}{l}\text { Hypoglycaemic } \\
\text { episodes }\end{array}$ & $22 \%$ & - & $10 \%$ & $123 \%(28$ to 292) & $9(5$ to 26$)$ \\
& - & $28 \%$ & $10 \%$ & $189 \%(70$ to 396$)$ & $6(4$ to 10$)$
\end{tabular}

${ }^{*}$ Abbreviations defined in glossary. $\mathrm{RRI}, \mathrm{NNH}$, and $\mathrm{Cl}$ calculated from data in article. $\dagger$ Values are mean change from baseline.

\section{ABSTRACTED FROM}

Farmer A, Wade A, Goyder E, et al. Impact of self monitoring of blood glucose in the management of patients with noninsulin treated diabetes: open parallel group randomised trial. BMJ 2007;335:132.

Correspondence to: Dr A Farmer, University of Oxford, Oxford, UK; andrew. farmer@dphpc.ox.ac.uk

Source of funding: National Health Service and National Institute for Health Research Health Technology Assessment Program; Abbott Diabetes Care provided blood glucose meters.

- Clinical impact ratings: IM/Ambulatory care 7/7; Endocrine 6/7; GP/FP/Primary care $5 / 7$
S ome experts consider SMBG to be an essential part of managing all patients with diabetes, especially those using insulin. Among patients who use tablets or diet to treat their diabetes, the benefit of SMBG has remained uncertain. Universal use of SMBG in this group has important cost- and treatment-burden implications. A meta-analysis supported by industry suggested benefit, ${ }^{1}$ although a Cochrane review concluded that more evidence was needed. ${ }^{2}$ The UK National Health Service funded the DiGEM trial to answer this question definitively.

The trial was designed to detect a potential dose-response relation across 3 groups: no SMBG, less-intensive SMBG, and more-intensive SMBG (with accompanying education). Participants had reasonably well-controlled diabetes at baseline. Somewhat surprisingly, more participants in the more-intensive self-monitoring group stopped doing SMBG than in the less-intensive group. This finding may reflect lack of interest in SMBG among study participants: Patients already monitoring were excluded from participation, and they may have derived greater benefit from intensive SMBG. Furthermore, patients in the more-intensive group who persisted with SMBG did monitor more often, but whether they accrued important benefits from SBMG remains unclear. Overall, the results suggest that the benefits of SMBG in patients treated with tablets are minimal at best.

In addition to considering the findings of this trial, clinicians should listen to what their patients have to say about SMBG. A recently published qualitative study of SMBG highlights, among other insights, that clinicians' focus on $\mathrm{HbA}_{1 \mathrm{c}}$ levels when assessing diabetes control may be interpreted by patients as indicating that SMBG is not important. ${ }^{3}$

\section{Frank Waldron-Lynch, MD}

Galway University Hospitals, Galway, Ireland Sean Dinneen, MD

National University of Ireland, Galway, Ireland

1. Sarol JN Jr., Nicodemus NA Jr., Tan KM, et al. Curr Med Res Opin 2005;21:173-84.

2. Welschen LM, Bloemendal E, Nijpels G, et al. Cochrane Database Syst Rev 2005;(2):CD005060.

3. Peel E, Douglas M, Lawton J. BMJ 2007;335:493 